\title{
Article \\ Determination of the Conservation State of Some Documents Written on Cellulosic Support in the Poni-Cernătescu Museum, Iași City in Romania
}

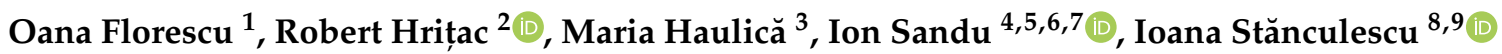 \\ and Viorica Vasilache ${ }^{4, *}$ (]) \\ check for \\ updates \\ Citation: Florescu, O.; Hrițac, R.; \\ Haulică, M.; Sandu, I.; Stănculescu, I.; \\ 1 Faculty of Geography and Geology, Doctoral School of Geosciences, "Alexandru Ioan Cuza” University, \\ 22 Carol I Bulevard, 700506 Iaşi, Romania; of.poni@gmail.com \\ 2 Faculty of Geography and Geology, "Alexandru Ioan Cuza” University, 22 Carol I Bulevard, \\ 700506 Iaşi, Romania; robert.hritac@gmail.com \\ 3 County Service of the National Archives Iasi, 26 Carol I Bulevard, 700505 Iaşi, Romania; \\ boutiucmariahaulica@gmail.com \\ 4 Department of Exact and Natural Sciences, Interdisciplinary Research Institute, "Alexandru Ioan Cuza" \\ University, 11 Carol I Bulevard, 700506 Iași, Romania; ion.sandu@uaic.ro \\ 5 Romanian Inventors Forum, 3 Sf. Petru Movila St., L11, III/3, 700089 Iaşi, Romania \\ 6 Academy of Romanian Scientists (AOSR), 54 Splaiul Independentei St., Sect. 5, 050094 Bucharest, Romania \\ National Institute for Research and Development in Environmental Protection, 294 Splaiul Independentei, \\ 6th District, 060031 Bucharest, Romania \\ 8 Department of Physical Chemistry, University of Bucharest, 4-12 Regina Elisabeta Bd., \\ 030018 București, Romania; ioana.stanculescu@gmail.com \\ 9 Horia Hulubei National Institute for Physics and Nuclear Engineering, 30 Aleea Reactorului, \\ 077125 Magurele, Romania \\ * Correspondence: viorica_18v@yahoo.com
} Vasilache, V. Determination of the Conservation State of Some Documents Written on Cellulosic Support in the Poni-Cernătescu Museum, Iași City in Romania. Appl. Sci. 2021, 11, 8726. https://doi.org/ 10.3390/app11188726

Academic Editor:

Snezana Agatonovic-Kustrin

Received: 23 August 2021

Accepted: 15 September 2021

Published: 18 September 2021

Publisher's Note: MDPI stays neutral with regard to jurisdictional claims in published maps and institutional affiliations.

Copyright: (c) 2021 by the authors. Licensee MDPI, Basel, Switzerland. This article is an open access article distributed under the terms and conditions of the Creative Commons Attribution (CC BY) license (https:// creativecommons.org/licenses/by/ $4.0 /)$.

\begin{abstract}
An important step in the conservation of old paper documents is the analysis of both the medium and the ink, in an attempt first to determine the extent of deterioration and degradation and then to choose the best preservation and restoration solutions. Our paper focuses on the analysis of three old documents displayed at the 'Poni-Cernătescu' Museum in Iaşi City, Romania by optical microscopy (OM), scanning electron microscopy and energy dispersive X-ray spectroscopy (SEMEDX), micro-FTIR spectroscopy and FT-Raman. Thus, the morphology and chemical composition of the paper media and the type of ink, as well as the cellulose crystallinity index were determined. PCA (Principal Component Analysis) was also used while relying on spectra collected by FTIR spectroscopy. We were able to determine the extent of degradation of the documents by corroborating all these findings.
\end{abstract}

Keywords: cultural artefacts; conservation; paper; ink; OM; SEM-EDX; micro-FTIR; FT-Raman; PCA

\section{Introduction}

Conservation science has an important role in practical conservation allowing the study of artefacts at chemical, physical and microstructural level, assisting a better understanding of the material disintegration and interaction processes due to the microclimate conditions in the storage and exhibition spaces. Quantitative data obtained from the analytical techniques (chemical composition, molecular weight, degree of polymerization, etc.) are very important for understanding the materials' properties and degrading processes that occur under the influence of the environmental factors [1,2].

The scientific substance of the document preservation measures is based on the elaboration of compatibility studies of the preventive and prophylactic preservation interventions applied to stop the evolutionary effects of deterioration and degradation. To this end, the aim is to determine the constituent materials (cellulose fibers, fillers, additives and 
adhesives used to obtain cellulose substrates and inks, etc.), knowledge of the normal structure and aspects related to natural aging, in time, and detailed knowledge of their behavior during storage, display/use in various cultural activities under the influence of endogenous and exogenous factors, clarification of the mechanisms of evolutionary effects of deterioration of physical condition and alteration of the chemical structure of component materials, and also the knowledge of the mechanisms that certain conservation treatments can trigger in the structure of materials [3].

Degradation of old documents on paper is a slow process that occurs over time at various rates depending on the environment/conditions in which they are kept. Optimal preservation conditions are required to recover and prolong the life and quality of old documents.

Steps to preserve old documents-manuscripts, incunabula, books, etc.-must be taken after the causes that trigger and influence the paper and ink degradation process have been analyzed and determined.

In-depth knowledge of a document in terms of structure or chemical composition of its materials is an absolute must in any preservation-restoration process [4]. State-of-the-art technical means, more specifically modern analytical chemistry methods are used for that purpose. Over time, paper media undergoes destructive processes due to the cleavage of macromolecular cellulose chains under the action of endogenous and exogenous factors, a phenomenon called paper aging [5].

As it ages, paper changes color turning light yellow to reddish brown [6]. The presence of biotic factors may cause certain areas on the cellulosic support to turn reddish brown, pink, grey, etc. $[7,8]$. In written documents, ink aging is one of the major causes of paper degradation, the mechanism of which depends on the nature of its components, especially of the ink and binder used, and on their interaction with the paper medium $[9,10]$.

The evolutionary degradation effect of manuscripts due to ferogallic inks is a major problem in the preservation of heritage collections, posing a serious threat to old documents over time. Ferogallic inks, in addition to the chelated complex obtained by coordinating the $\mathrm{Fe}^{2+}$ ion with galloyl-type phenolic compounds with three $\mathrm{OH}$ groups, under the name of iron (II) gallotanate, is the result of combining two natural organic acids (gallic and tannic) with $\mathrm{Fe}^{2+}$ salts. [11]. In the ink manufacturing process, along with white wine, Arabica gum is used as binder $[12,13]$.

It is known that ferogallic inks, depending on the manufacturing technology, induce by hydrolysis an acidic $\mathrm{pH}$ during writing and in the subsequent period of use and storage, which weakens the cellulosic polymer over time, and by migration or diffusion, halos with chromatic deviations result [13].

Starting from the results obtained in some studies made on paper documents from 1870-1890 [14-16], we intend to complete them with the study of three old documents from the 'Poni-Cernătescu' Museum, which were found in a book on the bookshelves of the renowned chemist professor PetruPoni (1841-1925). They were analyzed by nondestructive techniques like OM, SEM-EDX, micro-FTIR and FT-Raman, to determine the morphology and chemical composition of the paper media and the type of ink, as well as the cellulose crystallinity index. The $\mathrm{OM}$ analysis highlights the morphology and distribution of cellulosic fibers from the paper, and also the ink penetration degree in the paper [17]. The SEM analysis confirmed the OM results, obtaining micrographs with higher magnification. On the areas where SEM analysis were performed, we could establish the elemental composition in gravimetric percentages [18]. FTIR analysis offers data about chemical bonding and molecular structure [19]. Raman Spectroscopy finds information about chemical structure, phase and polymorphy, crystallinity and molecular interactions. It is based upon the interaction of light with the chemical bonds within a material [20].

PCA (Principal Component Analysis) was used on the FTIR spectra, the purpose being to determine the extent of degradation of the documents by corroborating all these findings.

The purpose of the paper is to establish the state of preservation of the documents under study, to establish an optimal protocol for preservation and restoration, as well as 
operations that must be performed before the museum displays the artifact. Both the paper supports, and the inks were taken into account.

\section{Materials and Methods}

\subsection{Materials}

The first document, marked S1, represents a chemistry test of the student M. Loebell and is $20 \mathrm{~cm}$ long and $16.9 \mathrm{~cm}$ wide (Figure 1). The second, marked S2, is a physics test of the student Gherman and is $34.2 \mathrm{~cm}$ long and $21 \mathrm{~cm}$ wide. It also contains the date when the test was taken (January 1872) (Figure 2). The third, marked S3, is V. Istrati's physics test and is $33.7 \mathrm{~cm}$ long and $21.1 \mathrm{~cm}$ wide. It also contains the date when the test was taken (1872) (Figure 3).

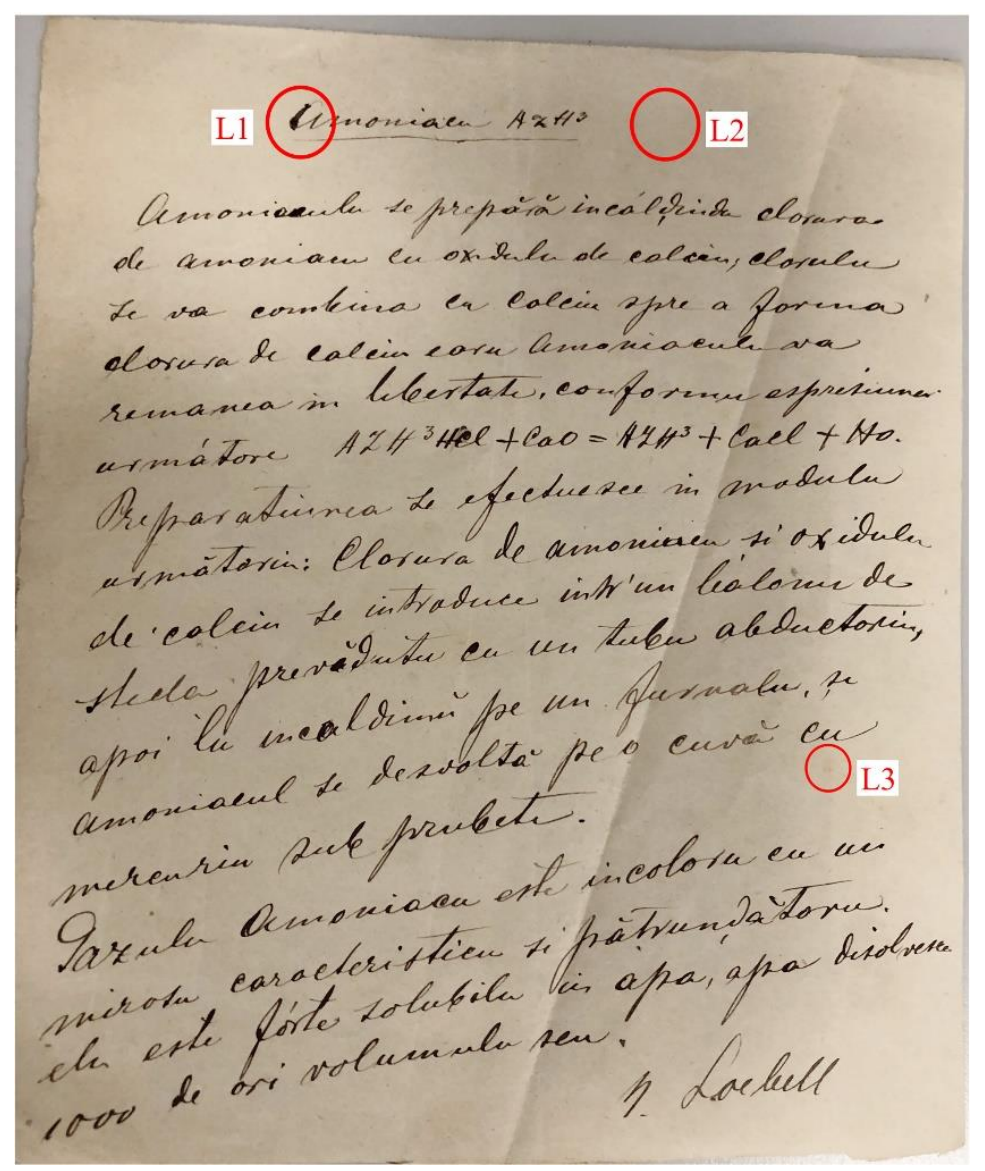

Figure 1. Student Loebell's chemistry test—S1 and the analyzed areas (L1, L2 and L3).

\subsection{Analytical Methods}

The following techniques were used to analyze the paper medium and the ink used: OM, SEM-EDX, micro-FTIR and FT-Raman spectroscopy. The tests were conducted directly on the material without sampling any specimens.

\subsubsection{OM}

A Zeiss Imager a1M microscope with an AXIOCAM camera and specialized software was used to analyze the surface morphology of the paper medium and of the inks used. Images were recorded at $\times 100$ magnification in a dark field. 


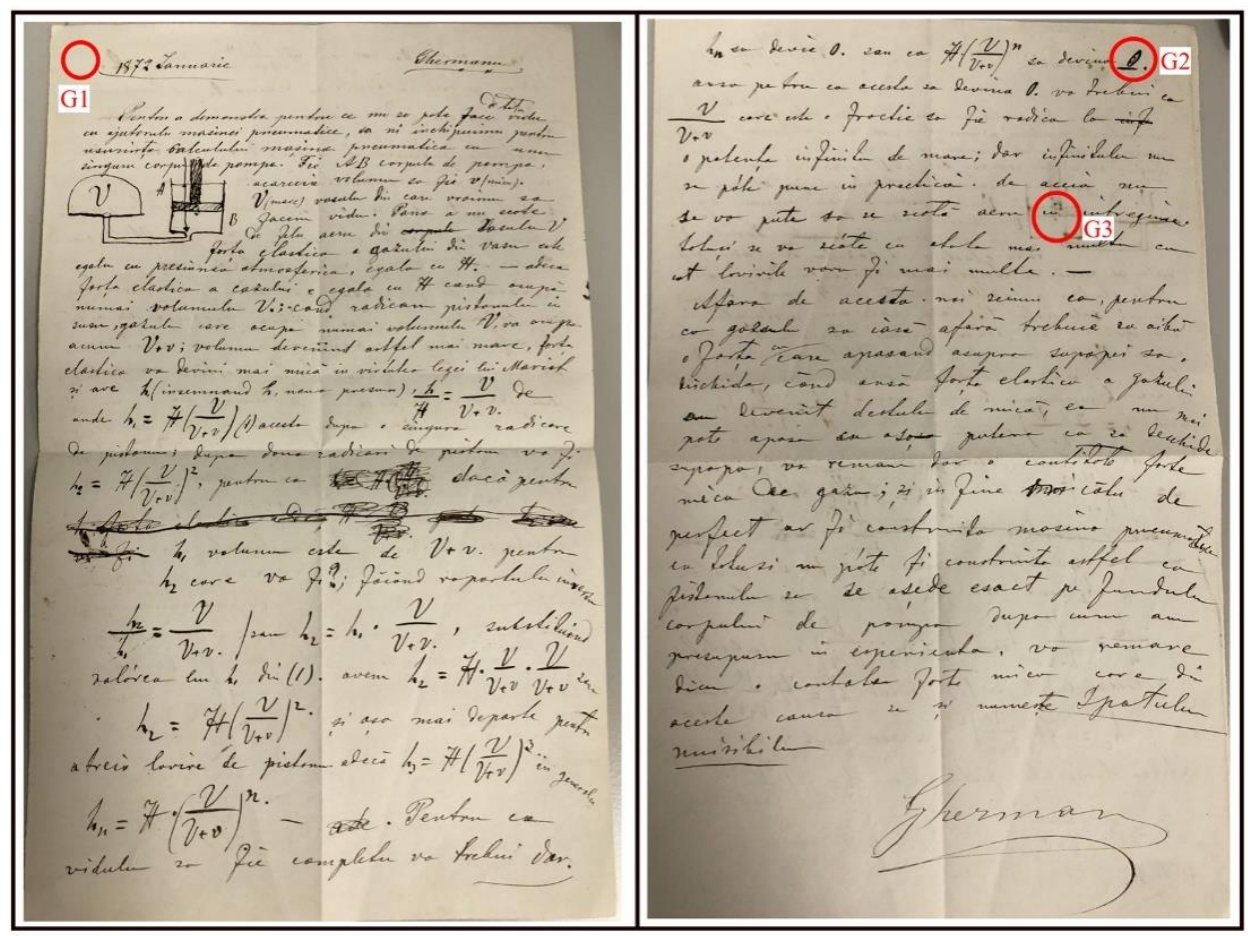

Figure 2. Student Gherman's physics test—S2 and the analyzed areas (G1, G2 and G3).

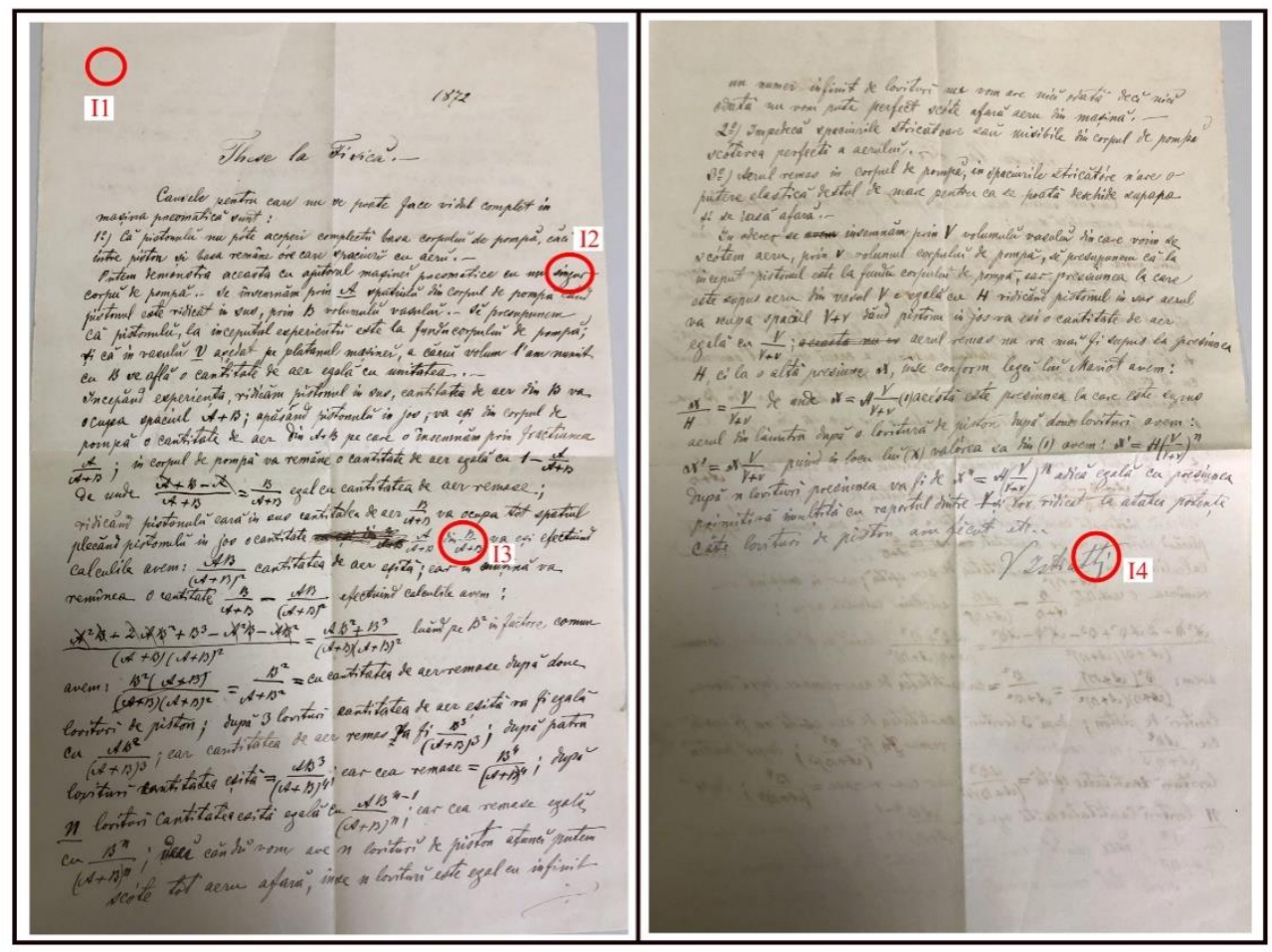

Figure 3. Student V. Istrati's physics test-S3 and the analyzed areas (I1, I2, I3 and I4).

\subsubsection{SEM-EDX}

A VEGA II LSH scanning electron microscope (SEM) manufactured by TESCAN Czech Republic, connected to a QUANTAX QX2 EDX detector manufactured by BRUKER/ROENTEC Germany and specialized software for spectral data processing, capable to process BSE (second diffused or scattered electrons) and SE (secondary electrons), were used to deter- 
mine structural features and elemental composition. Microphotographs of the analyzed specimens were taken with a BSE detector at magnifications ranging from $\times 200$ to $\times 500$.

\subsubsection{Micro-FTIR}

FTIR spectra were recorded using a TENSOR 27 FTIR spectrophotometer connected to a HYPERION 1000 microscope, both manufactured by Bruker Optic, Germany. The software is OPUS/VIDEO for interactive video data acquisition. The MCT detector is cooled with liquid nitrogen $\left(-196^{\circ} \mathrm{C}\right)$. We worked in reflection, within the $4000-600 \mathrm{~cm}^{-1}$ spectral range.

\subsubsection{FT-Raman}

A Bruker Vertex 70 spectrometer equipped with a RAM II module and Raman probe was used for FT-Raman in situ non-destructive measurements. Data were acquired and processed with the OPUS software using the vectorial normalization, default baseline correction and peak picking method.

Raman sample compartment and mobile Raman probe measurements were performed. The quality of the spectra obtained with the Raman probe is lower than the ones obtained in the Raman compartment, but it is the only option to measure heritage objects that do not fit in the sample measurement compartment of the spectrometer. The samples were placed in the sample holder, i.e., on the mobile stage for the Raman probe measurement, optimizing the position of the samples to obtain the highest peak intensity. FT-Raman spectra were recorded using Nd:YAG laser excitation of $1064 \mathrm{~nm}$, LN2 cooled Ge detector and source power ranging from 1 to $500 \mathrm{~mW}$, taking care to avoid fluorescence and sample combustion which may appear at higher laser power. Spectra acquisition within the 50 and $3500 \mathrm{~cm}^{-1}$ range was achieved using 256 or 512 scans at $4 \mathrm{~cm}^{-1}$ resolution.

\subsubsection{Chemometric Analysis of FTIR Data}

The data were analyzed using the 'FactoMine $R^{\prime}$ and 'factoextra' packages of the $\mathrm{R}$ program. The PCA method was used for the exploratory analysis of the entire ten FTIR spectra as observations, with the absorbance values as variable. Preprocessing of data consisted in the normalization of FTIR spectra.

PCA is the first step taken in data analysis with a view to outlining a pattern relying on the data set. It reduces the data set without losing the original data information. The newly generated main components, which are not correlated with one another, explain the information in the original data set [21].

The original spectra were organized into an X-shaped matrix $(I \times J)$, in which each replica was considered a sample. In this method, a J-dimensional X matrix was designed in a K-dimensional space, by decomposition into scores $\mathrm{S}(\mathrm{I} \times \mathrm{K})$ and loadings $\mathrm{L}(\mathrm{J} \times \mathrm{K})$, matrices whose product models the systematic variation of data, and a residual matrix $\mathrm{R}$ $(\mathrm{I} \times \mathrm{J})$ containing erroneous measurements. The diagram of two columns in the S score matrix relative to each other provides two-dimensional projection of the original data set, while the graph in the columns of the loading matrix L displays the correlation between the variables.

\section{Results and Discussions}

\subsection{OM Analysis}

Revealed the morphology and distribution of cellulosic fibers in paper and ink (Figure 4). Thus, the paper was found to be industrial and the ink ferro-gallic $[9,10,22]$. Free sulfate anion, resulting from the formation of the chelated complex on the paper support due to acid hydrolysis migrated in the vicinity of the writing and on the back of the page (Figure 5), transferring a reverse brown writing [3,23,24]. Its effect is to depolymerize cellulose which automatically induces a decrease in mechanical strength, through weakening of the support and chromatic changes in it. 

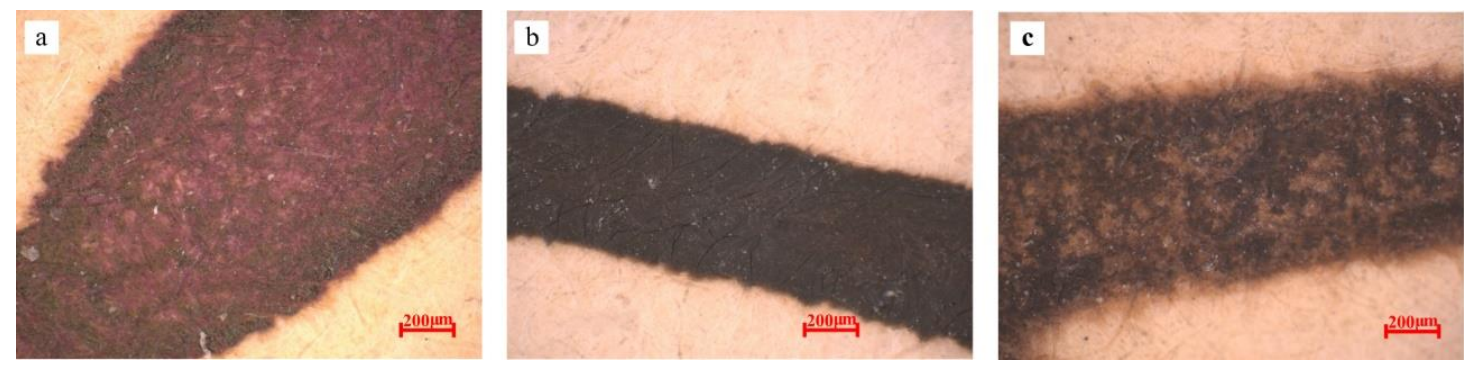

Figure 4. OM images of written documents: (a) S1; (b) S2; (c) S3.
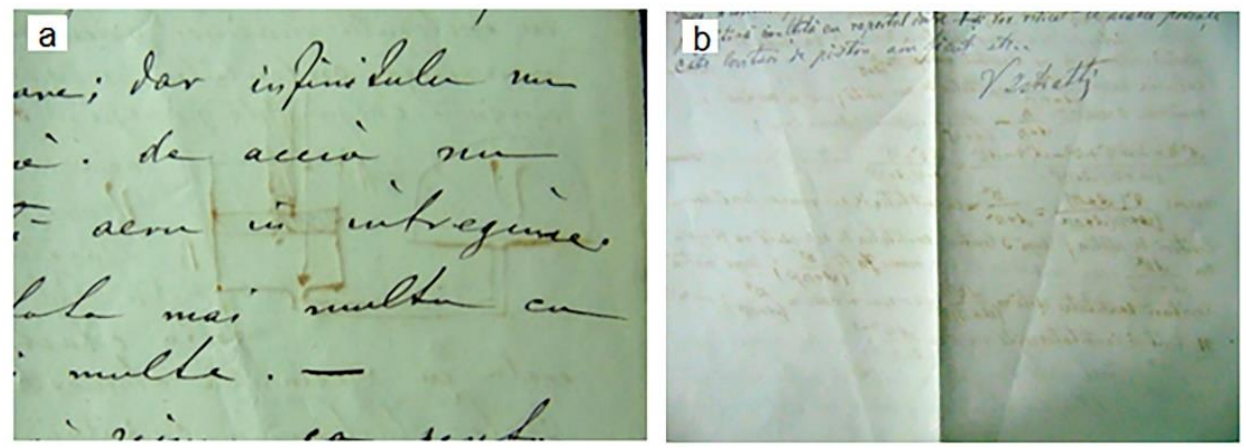

Figure 5. Migration of the sulfate anion with acid hydrolysis on the back of the page: (a) S2 and (b) S3.

\subsection{SEM Analysis}

Simultaneously produced microtopographic images and determined the morphology of surface structure components, while EDX revealed the elemental composition [25]. SEM microphotographs show the specific filaments of cellulose fibers and the filling material (Figure $6 \mathrm{a}-\mathrm{c}$ ). These stand out very clearly, in the form of three-dimensional networks, which can move independently of the others, thus providing good paper flexibility.
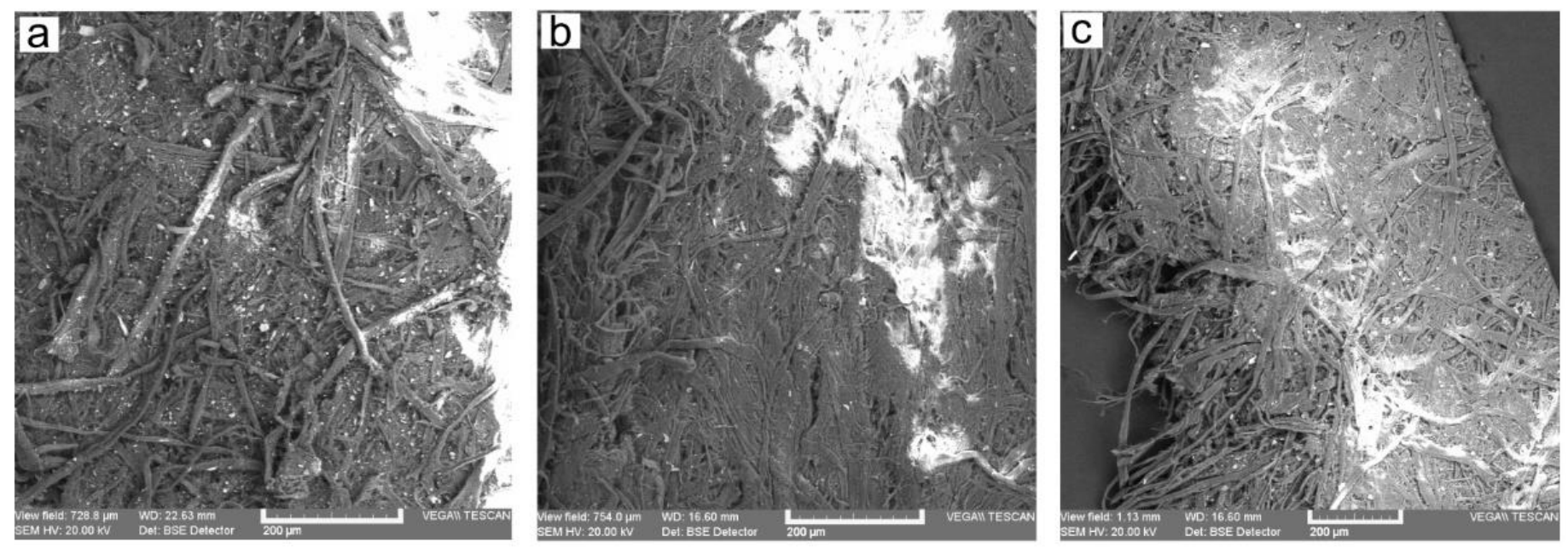

Figure 6. SEM microphotographs of the analyzed documents: (a) S1 $(\times 500),($ b) S2 $(\times 300),($ c) S3 $(\times 200)$.

EDX analysis conducted on the three documents revealed the presence of $\mathrm{C}, \mathrm{O}, \mathrm{Si}, \mathrm{Al}$, $\mathrm{Ca}$ and $\mathrm{S}$ in all the samples; in addition, the samples marked $\mathrm{S} 2$ and $\mathrm{S} 3$ also contained $\mathrm{Mg}$, $\mathrm{Na}, \mathrm{Cl}$ and $\mathrm{P}$ (Table 1). 
Table 1. Elemental composition of the three documents.

\begin{tabular}{ccccccccccc}
\hline \multirow{2}{*}{ Sample } & \multicolumn{8}{c}{ Elemental Composition in Gravimetric Percentages (\%) } \\
\cline { 2 - 11 } & $\mathbf{C}$ & $\mathbf{O}$ & $\mathbf{S i}$ & $\mathbf{A l}$ & $\mathbf{C a}$ & $\mathbf{M g}$ & $\mathbf{N a}$ & $\mathbf{P}$ & $\mathbf{C l}$ & $\mathbf{S}$ \\
\hline S1 & 36.62 & 60.50 & 0.42 & 0.77 & 1.02 & - & - & - & - & 0.67 \\
\hline S2 & 29.93 & 63.02 & 1.01 & 1.59 & 0.67 & 0.93 & 1.39 & 0.42 & 0.58 & 0.46 \\
\hline S3 & 30.92 & 62.52 & 1.08 & 1.84 & 0.72 & 0.70 & 1.25 & 0.27 & 0.32 & 0.38 \\
\hline
\end{tabular}

Elemental composition revealed the following data and facts:

- The lack of Mg in sample S1 is proof of the fact that the filling material does not contain talc, a material used to achieve an opaque and smooth paper surface [14]. Calcium carbonate $\left(\mathrm{CaCO}_{3}\right)$ was used as a filler, which was also confirmed by the characteristic band within the $1400-1500 \mathrm{~cm}^{-1}$ range revealed by micro-FTIR analysis (Figure 7). Calcium carbonate stabilizes the carboxylic groups of cellulose and makes it possible to increase paper aging stability [25].

- $\quad$ The presence of $\mathrm{Si}$ and $\mathrm{Al}$ accounts for the use of kaolinite $\left(\mathrm{Al}_{4}\left[(\mathrm{OH})_{8} \mid \mathrm{Si}_{4} \mathrm{O}_{10}\right]\right)$ to increase paper opaqueness and whiteness, which was also confirmed by the $1029 \mathrm{~cm}^{-1}$ peak. Sample S1 has the smallest amount of kaolinite.

- Documents S2 and S3 were treated with calcium hydroxide and with lye/caustic soda $(\mathrm{NaOH})$, which is accounted for by the $\mathrm{Ca}$ and Na contents.

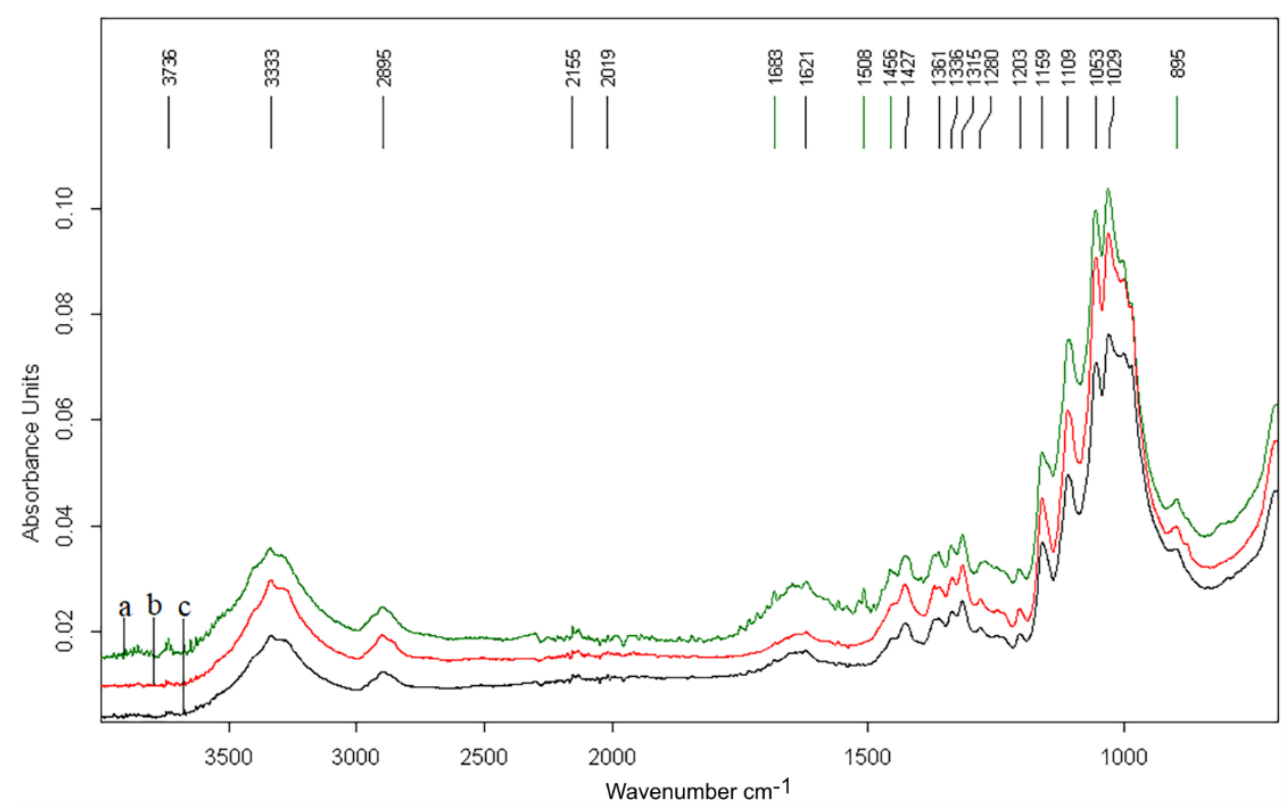

Figure 7. FTIR spectra on the paper medium of the three documents: (a) S1; (b) S2; (c) S3.

Saponified rosin glue mixed with aluminum sulfate and added with alum, is demonstrated by the presence of: $\mathrm{Na}, \mathrm{Al}$ and $\mathrm{S}$. Saponified rosin glue may have been used as gluing agent, as it was commonly used between 1807 and 1880 [23]. This gluing system provides alkaline conditions. After 1876, aluminum sulphate was used, which is thought to be the main source of acidity in paper (the $\mathrm{pH}$ is 3.8 to 4.5 ). Aluminum sulphate hydrolyses, and the result of this hydrolysis process is the hexahydro-aluminum acid complex [26] and sulphuric acid which has a strong destructive effect on cellulose fibers $[27,28]$. Acidity also occurs during paper bleaching treatments, due to the oxidation products in lignin.

Alum was used as a mordant, an assumption proven by the presence of $\mathrm{Al}$ and $\mathrm{S}$. The use of aluminum in paper manufacturing is one of the main causes of paper degradation. Aluminum compounds have been used to reduce the hydrophilic character of paper. 
In concentrations higher than $610 \mathrm{ppm}[29,30]$, they hydrolyze and contribute to the acidification of paper, which causes cellulose embrittlement and leads to poorer crystallinity (depolymerization). On the other hand, calcium and magnesium have positive effects on cellulose stability. When the aluminium content is less than $610 \mathrm{ppm}$ and the calcium or magnesium content is below $5000 \mathrm{ppm}$ and $800 \mathrm{ppm}$, respectively, paper samples are acidic, and when the aluminium content is below $610 \mathrm{ppm}$ and the calcium or magnesium content is greater than $5000 \mathrm{ppm}$ and $800 \mathrm{ppm}$, respectively, the paper is alkaline.

In addition to fillers and gluing agents, paper also contains additives meant to improve the characteristics of the cellulosic support of the documents. In our case, starch was used to improve the dry paper. It can be injected deep into the product or on its surface. Surface starch has the disadvantage that it can be easily decomposed both thermochemically and enzymatically and it is easy to hydrolyze $[4,7]$.

Optical bleaches contain $\mathrm{Cl}$ and are used to prevent cellulose from acquiring a yellowish hue [25].

Since the preservation of the documents' integrity could not allow performing the EDX elemental analysis on the inks, we had to use non-destructive methods (micro-FTIR and FT- Raman) to confirm the OM observations.

\subsection{Micro-FTIR}

The spectra recorded for the three paper samples were compared and the functional groups characteristic of paper [31] were identified (Figure 7). Thus, within the $2000-4000 \mathrm{~cm}^{-1}$ range, the presence of valence vibrations was identified for $\mathrm{OH}$ groups, with a $3333 \mathrm{~cm}^{-1}$ peak, $\mathrm{CH}$ and $\mathrm{CH} 2$ with a $2895 \mathrm{~cm}^{-1}$ peak; the $1500-2000 \mathrm{~cm}^{-1}$ range shows poor absorption at $1621 \mathrm{~cm}^{-1}$ due to symmetrical water molecule deformation vibrations (cellulose moisture).

The 1200-1500 $\mathrm{cm}^{-1}$ wavelength range contains a series of distinct bands of the $\mathrm{CH}_{2} \mathrm{OH}$ primary alcohol group with peaks at $1427 \mathrm{~cm}^{-1}, 1361 \mathrm{~cm}^{-1}, 1280 \mathrm{~cm}^{-1}$ and $1203 \mathrm{~cm}^{-1}$ due to deformation vibrations. Additionally, the deformation vibrations of the $\mathrm{C}-\mathrm{O}$ and $\mathrm{C}-\mathrm{H}$ bonds are found within this same range.

The $950-1200 \mathrm{~cm}^{-1}$ range contains the valence vibrations of the $\mathrm{C}-\mathrm{O}, \mathrm{C}-\mathrm{C}$ bonds of the pyranose cycles, which peak at $1053 \mathrm{~cm}^{-1}$, and the deformation vibrations of the $\mathrm{CH}_{2} \mathrm{OH}$ groups. The area ranging from $1430 \mathrm{~cm}^{-1}$ to $850 \mathrm{~cm}^{-1}$ is the fingerprint area, which is the most complex [32].

Within the $750-900 \mathrm{~cm}^{-1}$ range, the $895 \mathrm{~cm}^{-1}$ band is due to the deformation vibrations of the $\mathrm{CH}_{2} \mathrm{OH}, \mathrm{CHOH}$ groups and pyranose cycles.

According to the $1508 \mathrm{~cm}^{-1}$ peak, the paper in the document marked S1 contains lignin, which is absent in documents S2 and S3.

All samples contain calcium carbonate, as shown by the $1428 \mathrm{~cm}^{-1}$ peak [5]. The $1315 \mathrm{~cm}^{-1}$ peak corresponds to $C$ black or amorphous carbon [33].

The $1683 \mathrm{~cm}^{-1}$ peak, which is hardly noticeable and visible only for S1, belongs to the $\mathrm{C}=\mathrm{O}$ band, which indicates cellulose hydrolysis and oxidation [34]. The peaks within the $1430-1350 \mathrm{~cm}^{-1}$ and $1610-1550 \mathrm{~cm}^{-1}$ ranges are thought to be generated by the carboxylic salts responsible for paper degradation. The group of absorption bands in the $1400-1200 \mathrm{~cm}^{-1}$ area corresponds to the crystalline component of cellulose.

The $895 \mathrm{~cm}^{-1}$ peak intensity is due to the amount of amorphous cellulose [5,35].

Structural organization was assessed by calculating the crystallinity index $\left(\mathrm{I}_{\mathrm{C}}\right)$, degree of lateral order extent $\left(\mathrm{G}_{\mathrm{OL}}\right)$ and intensity of hydrogen bonds $\left(\mathrm{I}_{\mathrm{legH}}\right)$.

$I_{\mathrm{C}}$ and $\mathrm{G}_{\mathrm{OL}}$ were determined by calculating the ratio between the absorbances of the bands specific to the crystalline and amorphous ranges of cellulose $\left(1372 \mathrm{~cm}^{-1}, 1429 \mathrm{~cm}^{-1}\right.$ and $2900 \mathrm{~cm}^{-1}, 893 \mathrm{~cm}^{-1}$ ), while the $\mathrm{I}_{\text {legH }}$ in the absorption band intensity ratio ranges from 3400 to $1320 \mathrm{~cm}^{-1}$ [31].

Table 2 shows the crystallinity index, the degree of lateral order and the intensity of hydrogen. Higher indices are correlated with the presence of larger amounts of type I cellulose. 
The data collected may be correlated with some degradation processes: in microclimate conditions, the evolution of IR parameters reflects the oxidation of amorphous areas.

Table 2. Crystallinity indices, degree of lateral order and intensity of hydrogen bonds calculated based on the FTIR spectra.

\begin{tabular}{cccc}
\hline Document & $\begin{array}{c}\text { Crystallinity Index } \\
\left(\mathbf{I}_{\mathbf{c}}\right)\end{array}$ & $\begin{array}{c}\text { Degree of Lateral } \\
\text { Order }\left(\mathrm{G}_{\mathrm{OL}}\right)\end{array}$ & $\begin{array}{c}\text { Intensity of Hydrogen } \\
\text { Bonds }\left(\mathrm{I}_{\text {legH }}\right)\end{array}$ \\
\hline $\mathrm{S} 1$ & $\mathrm{~A}_{1363} / \mathrm{A}_{2905}=1.82$ & $\mathrm{~A}_{1424} / \mathrm{A}_{896}=0.67$ & $\mathrm{~A}_{3337} / \mathrm{A}_{1315}=0.95$ \\
\hline $\mathrm{S} 2$ & $\mathrm{~A}_{1370} / \mathrm{A}_{2904}=1.53$ & $\mathrm{~A}_{1429} / \mathrm{A}_{896}=0.34$ & $\mathrm{~A}_{3334} / \mathrm{A}_{1316}=1.03$ \\
\hline $\mathrm{S} 3$ & $\mathrm{~A}_{1363} / \mathrm{A}_{2899}=1.66$ & $\mathrm{~A}_{1429} / \mathrm{A}_{893}=0.55$ & $\mathrm{~A}_{3335} / \mathrm{A}_{1317}=1$ \\
\hline
\end{tabular}

When comparing the three ink spectra (Figure 8) with their paper counterparts, we noticed that the former resembled the latter, yet they were slightly flattened or had slightly shifted. Moreover, the 786, 756 and $733 \mathrm{~cm}^{-1}$ peaks in S3, the $853 \mathrm{~cm}^{-1}$ peak in $\mathrm{S} 2$ and the $1582 \mathrm{~cm}^{-1}$ peak in $\mathrm{S} 1$ may be attributed to ferro-gallic ink.

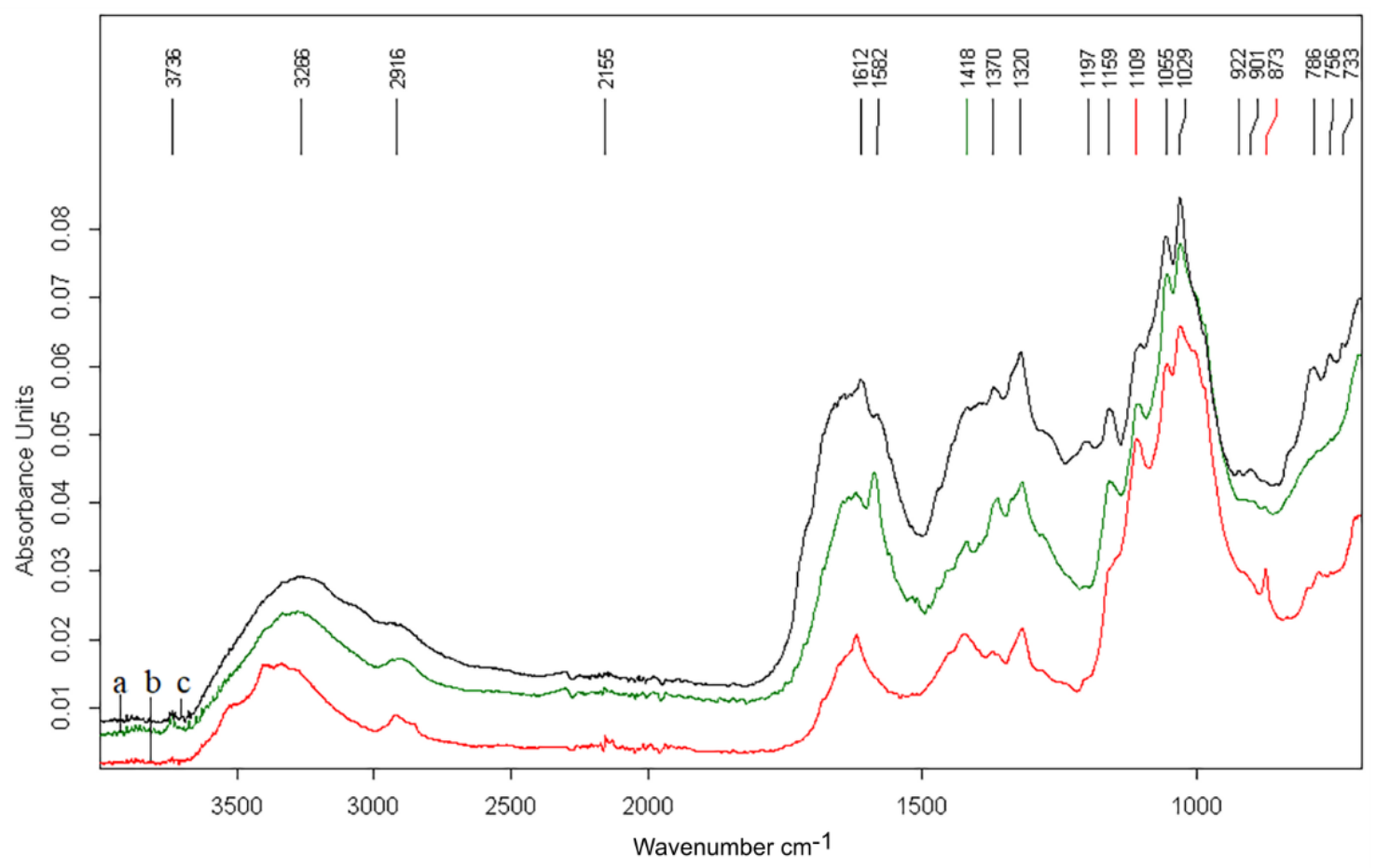

Figure 8. Ink on the three paper media: (a) S1, (b) S2, (c) S3.

\subsection{FT-Raman Spectroscopy}

FT-Raman spectra of natural organic materials show vibrational bands in two important areas: $2600-3500 \mathrm{~cm}^{-1}$ where the bands referring to the elongation vibrations of the $\mathrm{CH}$ bonds are present and $200-1800 \mathrm{~cm}^{-1}$ where the vibration bands specific to the $\mathrm{C}-\mathrm{H}$, $\mathrm{C}=\mathrm{O}, \mathrm{C}-\mathrm{O}$ etc. bonds are present [36].

Figure 9 shows the FT-Raman spectra for the three types of documents. The $1096 \mathrm{~cm}^{-1}$ peak [37] is specific to calcium carbonate, which is present in all three samples.

The presence of the $2895 \mathrm{~cm}^{-1}$ band in all the samples and the absence of the $2944 \mathrm{~cm}^{-1}$ and $2969 \mathrm{~cm}^{-1}$ bands (present in hydrated paper) indicate that the paper medium is dehydrated [38]. 


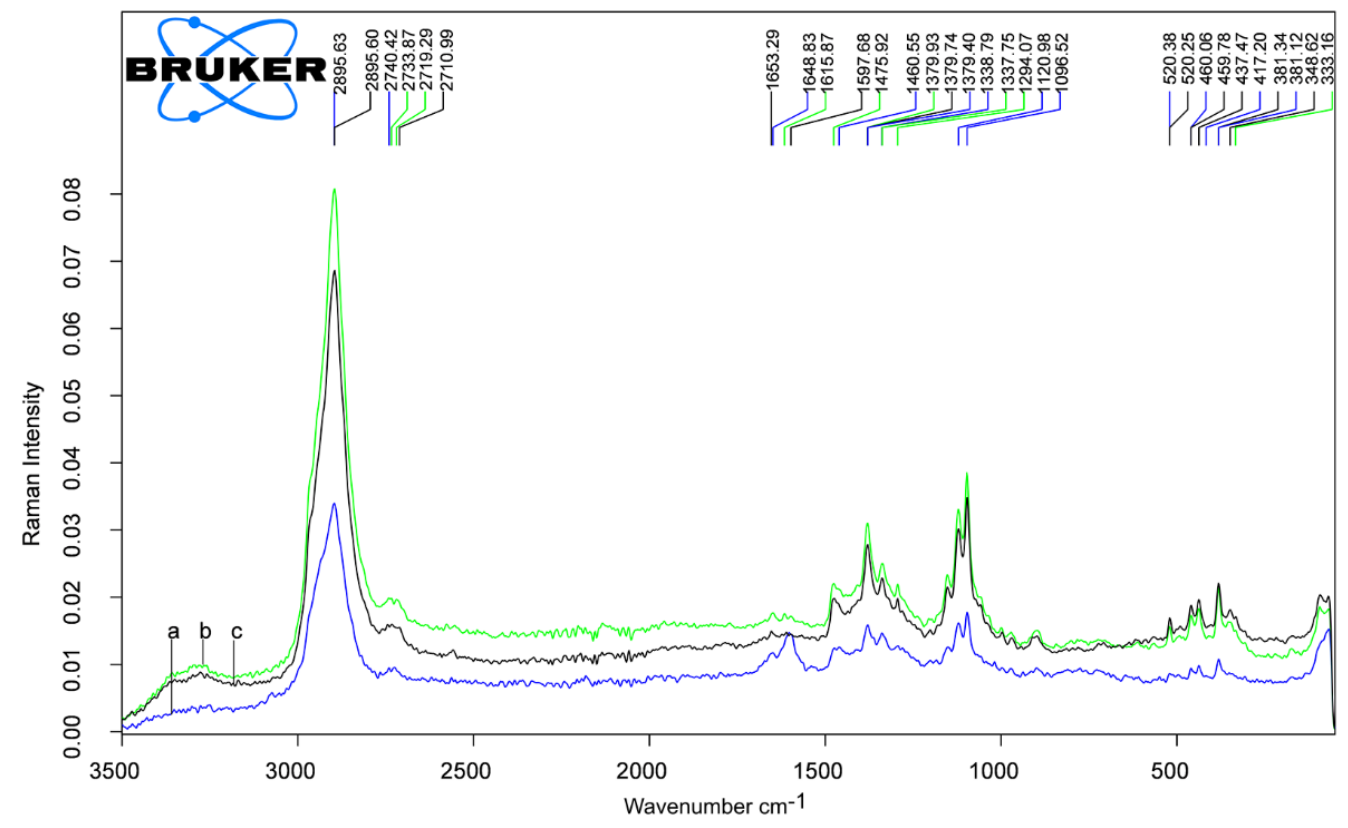

Figure 9. FT-Raman spectra for paper medium: (a) S1, (b) S2, (c) S3.

As far as the $\mathrm{S} 1$ document is concerned, the $1615 \mathrm{~cm}^{-1}$ peak (very strong signal) and the $1294 \mathrm{~cm}^{-1}$ peak prove the presence of lignin $[5,35,38,39]$. With the introduction of wood in the manufacture of paper (early nineteenth century), a greater amount of lignin was used. The lignin used to manufacture paper is responsible for the main degradation processes due to photo-oxidation $[35,38]$. Document S2 shows lignin according to the $1294 \mathrm{~cm}^{-1}$ peak (average signal) $[35,38]$. The $1120 \mathrm{~cm}^{-1}$ peak decreases with the aging of the paper medium [40] and is a clear indication of the fact that the documents are degraded.

We found the $520 \mathrm{~cm}^{-1}, 460 \mathrm{~cm}^{-1}, 437 \mathrm{~cm}^{-1}$ and $417 \mathrm{~cm}^{-1}$ peaks within the $300-600 \mathrm{~cm}^{-1}$ range, due to the presence of $\mathrm{C}-\mathrm{X}$ bonds $(\mathrm{X}=$ halogen: $\mathrm{Cl}, \mathrm{Br}, \mathrm{I})$, as well as of plane deformations of the benzene ring [41].

The $381 \mathrm{~cm}^{-1}$ peak is specific to amorphous cellulose and may be used to determine cellulose crystallinity using the following formula [39]:

$$
\mathrm{Cr}_{\text {Raman }}=\left[\left(\mathrm{I}_{380} / \mathrm{I}_{1096}\right)-0.0286\right] / 0.0065
$$

The results presented in Table 3 show that samples S1 and S3 have rather close crystallinity indices (95.83 and 92.52 , respectively), which are higher than that of sample S2, which means that document S2 is more degraded than the other two.

Table 3. Crystallinity indices calculated according to Raman spectra.

\begin{tabular}{cc}
\hline Document & Crystallinity Indices \% \\
\hline S1 & 95.83 \\
\hline S2 & 81.12 \\
\hline S3 & 92.52 \\
\hline
\end{tabular}

Figure 10 shows Raman spectra for the document ink where one may notice, just like in the FTIR spectra, the presence of peaks that are flatter and slightly shifted as compared to their paper counterparts allowing us to conclude that the ink presence is hardly distinguished in this case due to a low concentration at the surface sample. 


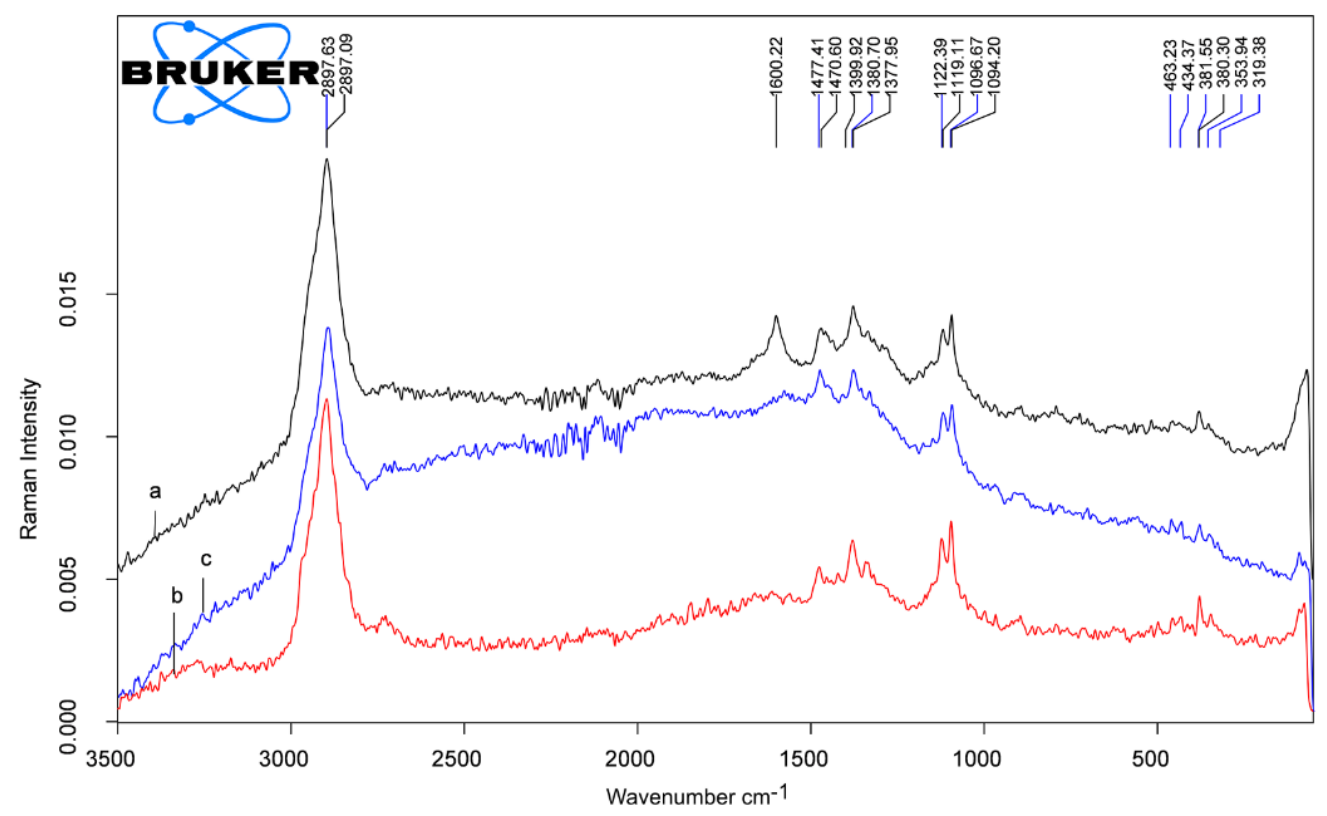

Figure 10. FT-Raman spectra for ink: (a) S1; (b) S2; (c) S3.

The FT-Raman absorption bands within the $1350-1400 \mathrm{~cm}^{-1}$ range are specific to amorphous carbon, whereas the $1470 \mathrm{~cm}^{-1}$ band is specific to ferro-gallic ink [35]. Thus, the ink used in writing the three documents is ferro-gallic, with an addition of amorphous carbon (carbon black).

\subsection{Chemometric Analysis of FTIR Data}

Most of the time, it is very difficult to determine the components present in the structure of the paper medium, in the pigments used to produce inks or in degradation products by spectral analysis [42]. FTIR spectra contain information that can be collected by statistical multivariate techniques. Thus, the differences between several similar spectra can be determined, and the chemometric analysis of the spectral data allows the extraction of additional data that bring about new information that is prone to interpretation [16,43].

PCA (Principal Component Analysis) based on the spectra acquired by FTIR spectroscopy was used to determine sample variability (Figure 11).

\section{Variances explained by Principal Components (\%)}

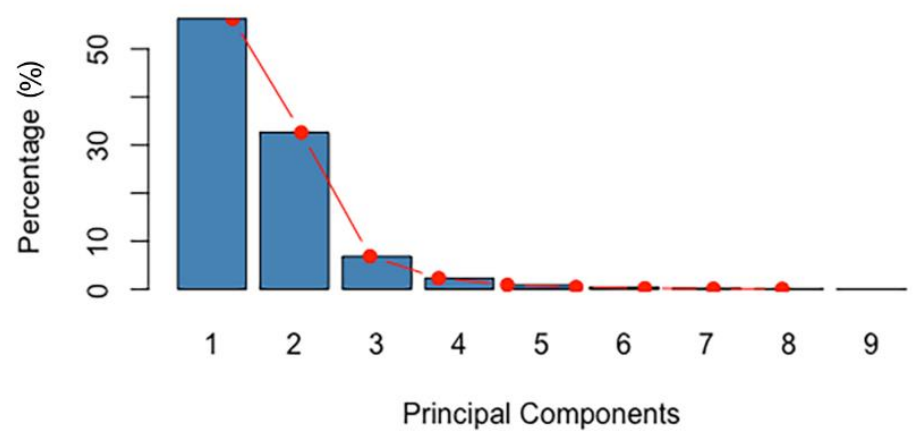

Figure 11. Variance percentage accounted for by the main components for the data in the IR spectrum.

As far as the data in the FTIR spectrum are concerned, the main component 1, represented on axis $X$ in Figure 12, accounts for $56.3 \%$ of the variance (variability), while the main component 2, represented on axis $\mathrm{Y}$, accounts for $32.7 \%$ of it. The determination coefficient $\mathrm{R}^{2}$ was also calculated for the first 3 main components (Figure 13). 


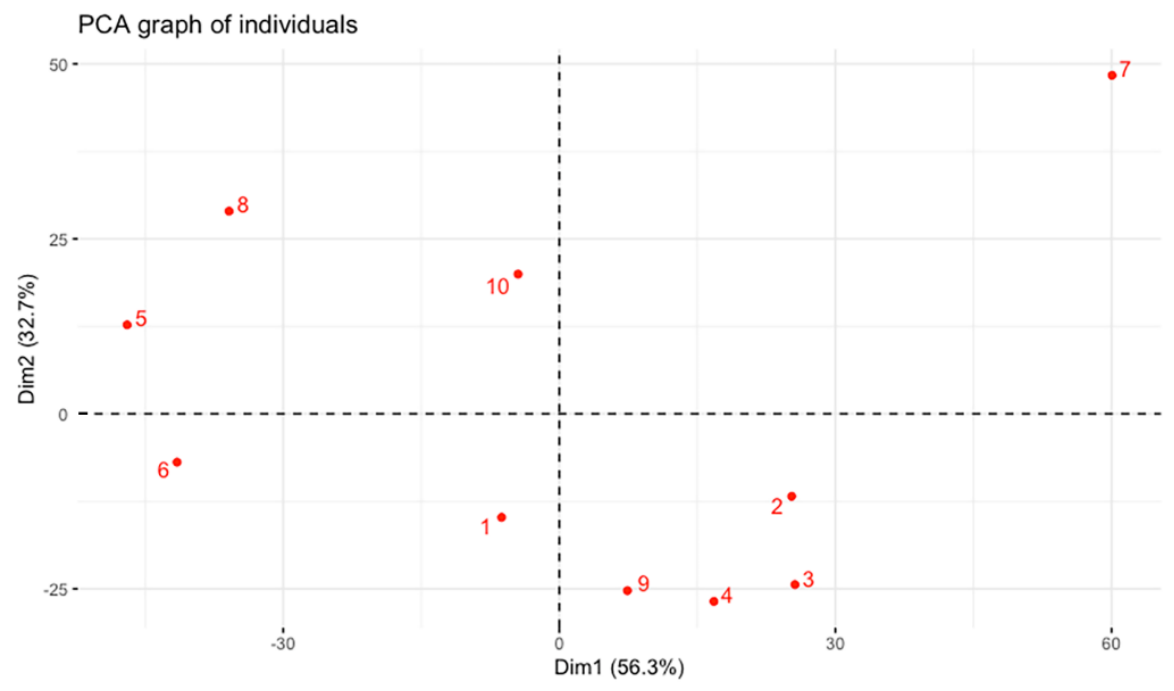

Figure 12. PCA of individual observations for the data in the FTIR spectrum: 1-G1; 2-G2; 3-G3; 4-I1; 5-L1; 6-L3; 7-I2; 8-L2; 9-I3; 10-I4.

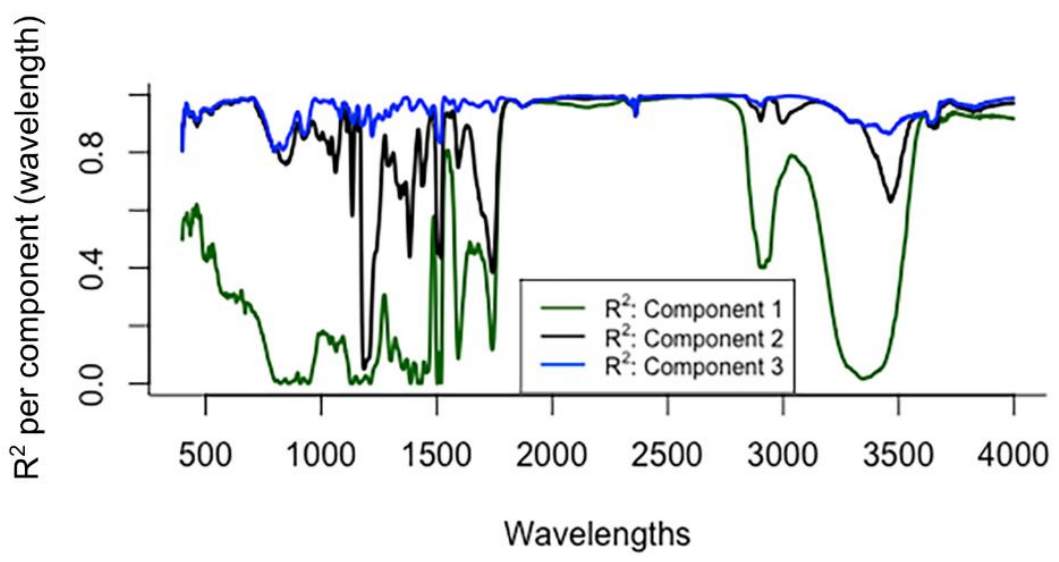

Figure 13. Determination coefficient $R^{2}$ for each main component.

The determination coefficient specifies how much of the variation of one variable is accounted for by the variation of the other variable (indicates the percentage of the total variation of the dependent variable that is accounted for by the independent variable). The correlation between samples is high when $\mathrm{R}^{2}$ is as close as possible to the unit (greater than 0.85 ), in our case (Figure 13) at $1500 \mathrm{~cm}^{-1}$, within the $2000-3000 \mathrm{~cm}^{-1}, 3500 \mathrm{~cm}^{-1}$ range.

A cluster analysis method was used to determine the links between the samples. The small number of samples $(n=10)$ determined the use of a non-hierarchical method, which is based on shifting observations from one group (cluster) to another during the analysis. The k-means method, implemented in R through the 'stats' package, is the most common. It starts from a random division of observations into k groups (clusters). For each stage, a mean of each group is calculated, and the items are shifted to the group whose mean is closest to them, until each item is part of the group with the closest mean (i.e., with characteristics as similar as possible), that is until no item needs shifting [44].

A shortcoming of the k-means method and of non-hierarchical methods, in general, is the need to specify a number of clusters by the initiator. When the number of clusters is not known in advance by objective criteria, it may be estimated by heuristic methods that help the initiator to choose the spot where a balance is struck between the degree of similarity between the items and the degree of generalization of the classification. In this case, we used the elbow method, which is based on determining an inflection point, and the silhouette method, which involves determining a value that expresses how similar an 
item is to the group (cluster) to which it belongs compared to other clusters. Considering the results of these methods, four clusters were used (Figure 14).

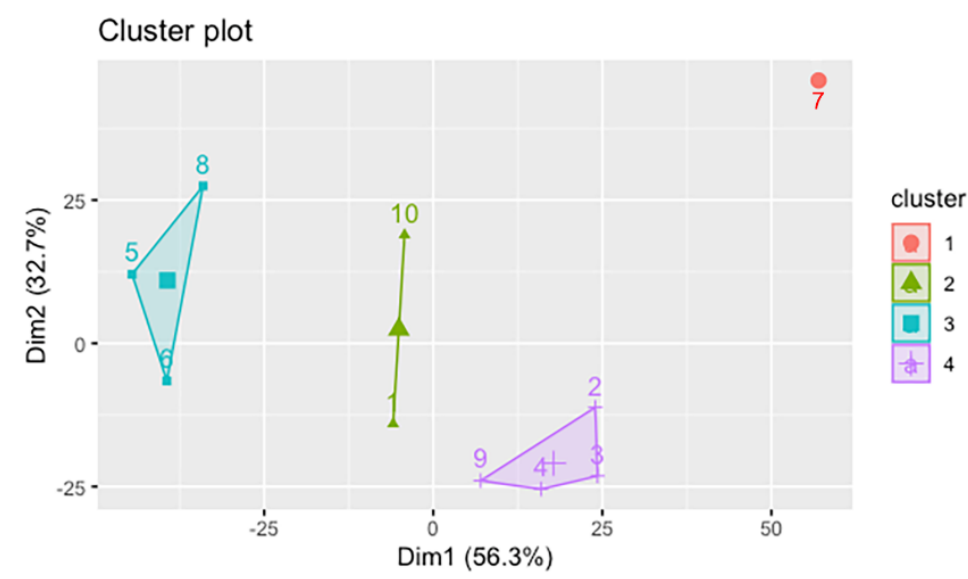

Figure 14. Cluster analysis by the k-means method $(\mathrm{n}=4)$ : 1-G1; $-\mathrm{G} 2 ; 3-\mathrm{G} 3 ; 4-\mathrm{I} 1 ; 5-\mathrm{L} 1 ; 6-\mathrm{L} 3$; 7-I2; 8-L2; 9-I3; 10-I4.

We found that the Loebell document samples $(5,6,8)$ formed a separate cluster (cluster $3)$, suggesting the existence of special paper characteristics, which is not the case with the Istrati and Gherman documents, which were grouped together in clusters 2 and 4 . Sample 7 (I2) was also a separate cluster.

\subsection{Recommendations for the Preservation of the Studied Documents}

As a result of the documents display in the open air for a long time, then in showcases and because the OM analysis showed not adherent dust deposits, first indicated was dry cleaning by dusting, then applying the ink washability test by the filter paper method. In case of washability, the writing will be protected with a solution of methyl-cellulose (drying layer) followed by a quick wash to avoid washing the protective material. Otherwise, washing by immersion in plain water will restore the hydrogen bonds to increase the strength of the cellulosic support.

The recommendation for preventive preservation is that the physical parameters of the microclimate are followed in the storage/preservation environment and their classification in intervals with optimal conservation values: $16-22{ }^{\circ} \mathrm{C}$ for temperature; $50-60 \%$-relative air humidity/air hygroscopicity; 50 lx for light/light radiation. It is also recommended to filter the air to prevent the penetration of dust carrying chemical and biological pollutants.

\section{Conclusions}

By corroborating the findings of the OM, SEM-EDX, micro-FTIR and Raman methods, we were able to conclude that the paper of the three documents had been obtained by industrial means from cellulose and that calcium carbonate had been added as filler and saponified rosin glue as the gluing agent. Kaolinite was used to increase the opaqueness and whiteness of the paper, and starch was used as an additive. Cl-based products were used as optical bleach.

Further to the calculation of the degree of crystallinity of the three documents, we found that document S1 is the best preserved, having the highest crystallinity index calculated both by the calculation formula for FTIR spectroscopy and by Raman spectroscopy, followed by documents S3 and S2.

The chemometric analysis of the spectra obtained by FTIR spectroscopy revealed that document S1 has special characteristics of its paper medium, different from documents S2 and S3, whose paper media have similar chemical composition.

After the performed investigations it was noticed that the documents state of conservation is good, and it is only necessary to dust and reduce the legibility of the halos. 
Preventive conservation recommendations are the physical parameters of the microclimate to have optimal values and, in order to prevent dust intrusion, air filtering is also recommended.

Author Contributions: Supervision and methodology, V.V. and I.S. (Ion Sandu); formal analysis and investigation, O.F.; V.V. and I.S. (Ioana Stănculescu); data curation and validation O.F.; V.V. and I.S. (Ion Sandu); writing—original draft preparation, O.F.; R.H.; M.H.; V.V. All authors have read and agreed to the published version of the manuscript.

Funding: This work was supported by a grant of the Ministry of Research, Innovation and Digitization CNCS/CCCDI-UEFISCDI, project number CNFIS-FDI-2021-0501.

Institutional Review Board Statement: Not applicable.

Informed Consent Statement: Not applicable.

Data Availability Statement: All required data provided in the manuscript.

Conflicts of Interest: The authors declare no conflict of interest.

\section{References}

1. Garside, P.; Knight, B. Strengthening the links between conservation analysis and conservation practice at the British Library. In Proceedings of the ICOM Committee for Conservation 17th Triennial Meeting, Melbourne, Australia, 19-23 September 2014.

2. Da Costa, P.L.L. European Coated Papers 1850-1975: Their Identification for Conservation Purposes. In Proceedings of the ICOM Committee for Conservation 16th Triennial Meeting, Lisbon, Portugal, 19-23 September 2011.

3. Boutiuc (Haulică), M. Aspecte moderne de prezervare a documentelor din arhive. In Teză de Doctorat; Universitatea Alexandru Ioan Cuza din Iasi: Iasi, Romania, 2020.

4. Sandu, I. Deteriorarea și Degradarea Bunurilor de Patrimoniu Cultural, Volume II; Editura Universității “Al.I.Cuza”: Iași, Romania, 2009.

5. Librando, V.; Minniti, Z.; Lorusso, S. Ancient and modern paper characterization by FTIR and micro-RAMAN spectroscopy. Conserv. Sci. Cult. Herit. 2011, 1, 249-268.

6. Nica-Badea, D. Factori și Procese Implicate în Degradarea Suporturilor Celulozice ale Bunurilor Culturale; din Târgu, J., Seria Mens Sana, N., Eds.; Analele Universității “Constantin Brâncuși”: Târgu Jiu, Romania, 2010; Volume 2, pp. 51-70.

7. Pasquarella, C.; Pasquariello, G.; Balocco, C.; Tarsitani, G.; Moroni, C.; Maggi, O.; Albertini, R. Preventive conservation of graphic collections; an integrated system of biologica land microclimatic monitoring. In Proceedings of the 5th International Congress on Science and Technology for the Safeguard of Cultural Heritage in the Mediterranean Basin, Istanbul, Turkey, 22-25 November 2011; pp. 321-326.

8. Stirbescu, N.M.; Ion, R.M.; Radu, A.; Teodorescu, S.; Bucurica, I.A.; Stirbescu, R.M.; Geba, M.; Dulama, I.D. Complex analitical investigations of old wax-Sealed Romanian paper documents. Rev. Chim. 2018, 69, 1608-1611. [CrossRef]

9. Da Costa, A.C.A.; Corrêa, F.D.N.; Sant'Anna, G.; Hannesch, O.; Tonietto, G.B.; Godoy, J.M.; Gonçalves, R.A.; Lutterbach, M.T.S. Iron-gall ink studies on acid and alkaline papers and their relation to cellulose microbiological degradation. Int. J. Conserv. Sci. 2018, 9, 413-428.

10. Viegas, R.; Corregidor, V.; Peña, M.T.; Alves, E.; Alves, L.C. Preliminary studies on iron gall inks composition using an external ion beam. Int. J. Conserv. Sci. 2013, 4, 593-602.

11. Stijnman, A. Iron-gall inks in history: Ingredients and production. In Iron Gall Inks: On Manufacture, Characterization, Degradation and Stabilization; Kolar, J., Strlič, M., Eds.; National and University Library: Ljubljana, Slovenia, 2006; pp. 25-167.

12. Ponce, A.; Brosto, L.B.; Gibbons, S.K.; Zavalij, P.; Viragh, C.; Hooper, J.; Gaskell, K.J.; Eichhorn, B. Elucidation of the Fe(III) Gallate Structure in Historical Irongall Inks. Anal. Chem. 2016, 88, 5152-5158. [CrossRef] [PubMed]

13. Díaz Hidalgo, R.J.; Córdoba, R.; Nabais, P.; Silva, V.; Melo, M.J.; Pina, F.; Teixeira, N.; Freitas, V. New insights into iron-gall inks through the use of historically accurate reconstructions. Herit. Sci. 2018, 6, 63. [CrossRef]

14. Doncea, S.M.; Ion, R.M.; Fierascui, R.C.; Bacalum, E.; Bunaciu, A.; Abdul-Enein, H.Y. Spectral Methods for Historical Paper Analysis: Composition and Age Approximation. Instrum. Sci. Tech. 2010, 38, 96-106. [CrossRef]

15. Kolar, J.; Strlič, M.; Lojewski, T.; Havermans, J.; Steemers, T.; de Bruin, G.; Knight, B.; Palm, J.; Hanus, J.; Perminova, O.; et al. Papertreat project-Preserving our paper-based collections. Durab. Paper Writ. 2008, 2, 5-7.

16. Gorassini, A.; Calvini, P.; Baldin, A. Fourier Transform Infrared Spectroscopy (FTIR) Analysis of Historic Paper Documents as a Preliminary Step for Chemometrical Analysis. In Multivariate Analysis and Chemometry Applied to Environment and Cultural Heritage, 2nd ed.; Bentham Science Publishers: Sharjah, United Arab Emirates, 2008.

17. Wang, J.; Ren, J.; Yuan, C.; Shen, Y.; Gan, Q.; Shi, J.; Liu, Q.; Shi, J. Non-invasive optical micro-identification of ink verification in penink handwriting. Results Chem. 2020, 2, 100025. [CrossRef]

18. Zadora, G.; Brozek-Mucha, Z. SEM-EDX-A useful tool for forensic examinations. Mater. Chem. Phys. 2003, 82, 345-348. [CrossRef] 
19. Mohamed, M.A.; Jaafar, J.; Ismail, A.F.; Othman, M.H.D.; Rahman, M.A. Chapter 1-Fourier Transform Infrared (FTIR) Spectroscopy. Membr. Charact. 2017, 3-29. [CrossRef]

20. McCreery, R.L. Raman Spectroscopy for Chemical Analysis; John Wiley \& Sons: New York, NY, USA, 2000.

21. Ferrer, N.; Sistach, M.C. Characterisation by FTIR Spectroscopy of Ink Components in Ancient Manuscripts. Restaurator 2005, 26, 105-117.

22. Poggi, G.; Giorgi, R.; Toccafondi, N.; Katzur, V.; Baglioni, P. Hydroxide Nanoparticles for Deacidification and Concomitant Inhibition of Iron-Gall Ink Corrosion of Paper. Langmuir 2010, 26, 19084-19090. [CrossRef] [PubMed]

23. Boutiuc (Haulica), M.; Florescu, O.; Vasilache, V.; Sandu, I. The Comparative Study of the State of Conservation of Two Medieval Documents on Parchment from Different Historical Periods. Materials 2020, 13, 4766. [CrossRef] [PubMed]

24. Sandu, I.C.A.; Sandu, I.; Popoiu, P.; van Saanen, A. Aspecte Metodologice Privind Conservarea Ştiinţifică a Patrimoniului Cultural; Corson: Iaşi, Romania, 2001.

25. Baglioni, P.; Chelazzi, D.; Giorgi, R. Deacidification of Paper, Canvas and Wood. In Nanotechnologies in the Conservation of Cultural Heritage; Springer: Dordrecht, The Netherlands, 2015; Volume 4, pp. 117-144. [CrossRef]

26. Barrow, W.Y. Deterioration of Book Stock. Causes and Remedies; Peter Peregrinus Ltd.: London, UK, 1959.

27. Gess, J.M. The sizing of paper with rosin and alaun at acid pHs. In Paper Chemistry, 2nd ed.; Roberts, J.C., Ed.; Blackie Academic \& Profesional: London, UK, 1996; pp. 120-139.

28. Area, M.C.; Cheradame, H. Paper aging and degradation: Recent findings and research methods. Bioresources 2011, 6, 5307-5337.

29. Stephens, C.H.; Barrett, T.; Whitmore, P.M.; Wade, J.A.; Mazurek, J.; Schilling, M. Composition and condition of naturally aged papers. J. Am. Inst. Conserv. 2008, 47, 201-215. [CrossRef]

30. Malutan, T.; Pui, A.; Obrocea, P.P. Spectroscopia IR a celulozelor obtinute prin procedeul sulfat cu aditivi. Rev. De Celul. Si Hârtie 2002, 51, 17-20.

31. Kruer-Zerhusen, N.; Cantero-Tubilla, B.; Wilson, D.B. Characterization of cellulose crystallinity after enzymatic treatment using Fourier transform infrared spectroscopy (FTIR). Cellulose 2017, 25, 37-48. [CrossRef]

32. Laserna, J.J. Modern Techniques in Raman Spectroscopy; John Wiley and Sons Ltd.: Chichester, NY, USA, 1996.

33. Zidan, Y.; El-Shafei, A.; Noshy, W.; Salim, E. A comparative study to evaluate conventional and nonconventional cleaning treatments of cellulosic supports. Mediterr. Archaeol. Archaeom. 2017, 3, 337-353.

34. Chiriu, D.; Ricci, P.C.; Cappellini, G. Raman characterization of XIV-XVI centuries Sardinian documents: Ink, paper and parchments. Vib. Spectrosc. 2017, 92, 70-81. [CrossRef]

35. Castro, K.; Perez-Alonso, M.; Rodriguez-Laso, M.D.; Etxebarria, N.; Madariaga, J.M. Non-invasive and non-destructive micro-XRF and micro-Raman analysis of a decorative wall paper from the beginning of the 19th century. Anal. Bioanal. Chem. 2007, 387, 847-860. [CrossRef] [PubMed]

36. Buzgar, N.; Apopei, A.I.; Buzatu, A. Romanian Database of Raman Spectroscopy. 2009. Available online: http:/ / rdrs.ro (accessed on 25 January 2020).

37. Chiriu, D.; Ricci, P.C.; Cappellini, G.; Salis, M.; Loddo, G.; Carbonaro, C.M. Ageing of ancient paper: A kinetic model of cellulose degradation from Raman spectra. J. Raman Spectrosc. 2018, 49, 1802-1811. [CrossRef]

38. Agarwal, U. $1064 \mathrm{~nm}$ FT-Raman spectroscopy for investigations of plant cell walls and others biomass materials. Front. Plant Sci. 2014, 5, 490. [CrossRef]

39. Zięba Palus, J.; Weselucha-Birczyńska, A.; Trzcińska, B.; Kowalski, R.; Moskal, P. Analysis of degraded papers by infrared and Raman spectroscopy for forensic purposes. J. Mol. Struct. 2017, 1140, 154-162. [CrossRef]

40. Parida, C.; Dash, S.K.; Pradhan, C. FTIR and Raman studies of cellulose fibers of Luffacylindrica. J. Compos. Mater. 2015, 5, 5-10.

41. Cortea, I.M. Contribuții la studiul proceselor de îmbătrânire în straturile picturale pe bază de răsini sintetice. In Teză de Doctorat; Universitatea Politehnica din București: București, Romania, 2017.

42. Silva, C.; Pimentel, M.F.; Amigo, J.M.; Garcia-Ruiz, C.; Ortega-Ojeda, F. Infrared spectroscopy and chemometrics to evaluate paper variability in document dating. Spectroscopy 2018, 30, 12-15.

43. Kumar, R.; Sharma, V. Chemometrics in forensic science. Trends Anal. Chem. 2018, 105, 191-201. [CrossRef]

44. Wilks, D. Statistical Methods in the Atmospheric Sciences, 2nd ed.; Academic Press: Amsterdam, The Netherlands; Boston, MA, USA, 2005. 